\title{
Tumors of the peripheral nervous system: analysis of prognostic factors in a series with long-term follow-up and review of the literature
}

\author{
Nicola Montano, MD, PhD, Quintino Giorgio D’Alessandris, MD, PhD, Manuela D’Ercole, MD, \\ Liverana Lauretti, MD, Roberto Pallini, MD, PhD, Rina Di Bonaventura, MD, \\ Giuseppe La Rocca, MD, Federico Bianchi, MD, and Eduardo Fernandez, MD \\ Institute of Neurosurgery, Catholic University, Rome, Italy
}

OBJECTIVE Only a few published studies of the surgical treatment of benign peripheral nerve sheath tumors (BPNSTs), malignant peripheral nerve sheath tumors (MPNSTs), and peripheral non-neural sheath tumors (PNNSTs) have analyzed the results and possible prognostic factors using multivariate analysis. The authors report on their surgical series of cases of BPNSTs, MPNSTs, and PNNSTs with long-term follow-up and analyze the role of selected factors with respect to the prognosis and risk of recurrence of these tumors using multivariate analysis. They also review the pertinent literature and discuss their results in its context.

METHODS The authors retrospectively reviewed data from cases involving patients who underwent resection of a peripheral nerve tumor between January 1983 and December 2013 at their institution. Of a total of 200 patients, 150 patients (with 173 surgically treated tumors) had adequate follow-up data available for analysis. Pain was assessed using a visual analog scale (VAS), and motor and sensory function were assessed by means of the Louisiana State University grading system. They also analyzed the relationship between tumor recurrence and patient sex, patient age, diagnosis of neurofibromatosis (NF), tumor histopathology, tumor size, tumor location, and extent of resection (subtotal vs gross-total resection), using univariate and multivariate analyses.

RESULTS There was a statistically significant improvement in the mean VAS pain score (preoperative $3.96 \pm 2.41$ vs postoperative $0.95 \pm 1.6, p=0.0001$ ). Motor strength and sensory function were significantly improved after resection of tumors involving the brachial plexus ( $p=0.0457$ and $p=0.0043$, respectively), tumors involving the upper limb ( $p=$ 0.0016 and $p=0.0016$, respectively), BPNSTs $(p=0.0011$ and $p<0.0001$, respectively), and tumors with dimensions less than $5 \mathrm{~cm}$ (motor strength: $p=0.0187$ and $p=0.0021$ for $\leq 3 \mathrm{~cm}$ and $3-5 \mathrm{~cm}$ tumors, respectively; sensory function: $p=0.0003$ and $p=0.0001$ for $\leq 3 \mathrm{~cm}$ and $3-5 \mathrm{~cm}$ tumors, respectively). Sensory function showed a statistically significant improvement also in patients who had undergone resection of tumors involving the lower limb $(p=0.0118)$. Total resection was associated with statistically significant improvement of motor strength $(p=0.0251)$ and sensory function $(p<0.0001)$. In univariate analysis, a history of NF $(p=0.0034)$, a diagnosis of MPNST or PNNST $(p<0.0001)$, and subtotal resection $(p=0.0042$ ) were associated with higher risk of tumor recurrence. In multivariate analysis (logistic regression analysis), a history of NF (OR 9.28\%, 95\% Cl 1.62-52.94, $p=0.0121)$ and a diagnosis of MPNST (OR 0.03\%, $95 \% \mathrm{Cl} 0.002-0.429, \mathrm{p}=0.0098$ ) or PNNST (OR 0.081\%, 95\% Cl 0.013-0.509, $\mathrm{p}=0.0077$ ) emerged as independent prognostic factors for tumor recurrence.

CONCLUSIONS A total resection should be attempted in all cases of peripheral nervous system tumors (irrespective of the supposed diagnosis and tumor dimensions) because it is associated with better prognosis in term of functional outcome and overall survival. Moreover, a total resection predicts a lower risk of tumor recurrence. Patients with a history of NF and tumors with malignant histology remain a challenge both for neurosurgeons and oncologists due to higher recurrence rates and the lack of standardized adjuvant therapies.

http://thejns.org/doi/abs/10.3171/2015.6.JNS15596

KEY WORDS peripheral nerve sheath tumors; prognostic factors; surgery

ABBREVIATIONS BPNST = benign PNST; MPNST = malignant PNST; NF = neurofibromatosis; OS = overall survival; $P$ PS = progression-free survival; PNNST = peripheral non-neural sheath tumor; PNST = peripheral nerve sheath tumor; VAS = visual analog scale.

SUBMITTED March 15, 2015. ACCEPTED June 17, 2015.

INCLUDE WHEN CITING Published online December 4, 2015; DOI: 10.3171/2015.6.JNS15596. 
$\mathrm{T}$ UMORs involving the peripheral nervous system can be intrinsic (peripheral nerve sheath tumors [PNSTs]) or extrinsic (peripheral non-neural sheath tumors [PNNSTs]), and both can be either benign or malignant. Benign peripheral nerve sheath tumors (BPNSTs) include schwannomas (also called neurilemmomas or neurinomas), the most common tumors arising from peripheral nerves, and neurofibromas. ${ }^{43}$ These lesions are usually well circumscribed, especially the schwannomas, and grow between the fascicles of peripheral nerves; schwannomas often undergo cystic and degenerative changes. ${ }^{28}$ Most cases are sporadic; however, some are associated with neurofibromatosis (NF) Type 1 and Type 2,33 schwannomatosis, or Carney's complex, ${ }^{28}$ and they may rarely occur following radiation..$^{45,50}$

Malignant peripheral nerve sheath tumors (MPNSTs) show variable differentiation toward one of the cellular components of nerve sheaths (Schwann cells, fibroblasts, and perineurial cells). ${ }^{51}$ MPNSTs account for 5\% to $10 \%$ of soft tissue sarcomas ${ }^{49}$ and have an incidence of $0.001 \%$ in the general population. ${ }^{4}$ Like BPNSTs, they can occur sporadically as well as in patients with NF (affecting $4 \%$ to $10 \%$ of patients with this condition $)^{4,22}$ and arise either de novo or from a preexisting neurofibroma or, rarely, schwannoma. ${ }^{51}$

PNNSTs are rare. As previously reported, ${ }^{34}$ benign PNNSTs include a number of lesions such as ganglion cysts of the peripheral nerve, localized hypertrophic neuropathy, lipomas, venous angiomas, hemangiopericytomas, glomus tumors, and hemangioblastomas. Myositis ossificans, osteochondromas, ganglioneuromas, meningiomas, cystic hygromas, myoblastomas or granular cell tumors, and epidermoid cysts are also included in the category of PNNST. ${ }^{34}$ Malignant PNNSTs can arise from tumors such as breast or lung cancers that directly extend or metastasize to a nerve, or they can be osteogenic or softtissue sarcomas that can displace or adhere to the nerve or encase it and, in a few cases, actually invade it. Lymphomas and melanomas can metastasize and secondarily involve the nerve,,$^{34}$ and primary lymphoma involving the peripheral nervous system has also been reported. ${ }^{16}$

Until now, various series have been published reporting the results of surgical treatment of these tumors. Obviously, they differ in number of patients, histopathology, location, follow-up, and methodological analysis of results. ${ }^{1-3}$, $5-15,17,19-21,23-27,29-32,35-42,44,46-48,52-59$

The aim of this study was to report the results of surgical treatment in our series of cases of BPNSTs, MPNSTs, and PNNSTs with long-term follow-up and to analyze the role of some clinical and surgical factors with respect to prognosis and the risk of tumor recurrence. We also review the pertinent literature and discuss our results in its context.

\section{Methods}

We retrospectively reviewed clinical and outcome data for cases in which a peripheral nerve tumor at any anatomical location was resected at the Institute of Neurosurgery, Catholic University, Rome, between January 1983 and December 2013. All operations were performed by the senior author (E.F.). Of a total of 200 patients, 150 (77 male, 73 female) had follow-up data available for analysis. These 150 patients underwent resection of a total of 173 tumors. The mean age of the patients at the time of the 173 operations was $46.94 \pm 15.47$ years. The mean duration of follow-up after resection was $112.14 \pm 81.10$ months (range 12-360 months). Clinical data are summarized in Table 1.

Changes in pain level were assessed using a visual analog scale (VAS). We evaluated motor and sensory outcome using the Louisiana State University (LSU) grading system, as described by Donner and colleagues. ${ }^{18}$ The neurological evaluation was performed by different physicians preoperatively and at follow-up.

We also studied the impact of sex, age, diagnosis of NF, tumor histopathology, tumor size, tumor location, and extent of resection (subtotal vs gross-total resection) on the recurrence of these tumors. Gadolinium-enhanced MRI studies were performed 3 months, 6 months, and 1 year after the operation and annually thereafter. Local recurrence was defined as evidence of a contrast-enhancing lesion on T1-weighted MR images obtained after gadolinium administration.

Statistical comparison of continuous variables and ordinal variables was performed by means of the Student's t-test and Wilcoxon signed-rank test, as appropriate. Comparison of categorical variables was performed by means of the $\chi^{2}$ statistic, using the Fisher exact test.

A multivariate logistic regression model was used to estimate the odds ratio for recurrence of tumor, while adjusting for baseline variables, including diagnosis of NF, tumor histopathology, tumor size, tumor location, and extent of resection. Differences were considered statistically

TABLE 1. Demographic and clinical characteristics of 150
patients (173 peripheral nerve tumors) operated on at the
Catholic University of Rome, January 1983-December 2013

\begin{tabular}{|c|c|}
\hline Characteristic & Value \\
\hline $\operatorname{Sex}(M / F)$ & $77 / 73$ \\
\hline Mean age (yrs) & $46.94 \pm 15.47$ \\
\hline No. of patients w/ NF & 13 \\
\hline \multicolumn{2}{|l|}{ Tumor histopathology } \\
\hline BPNST & 135 \\
\hline MPNST & 6 \\
\hline PNNST & 32 \\
\hline \multicolumn{2}{|l|}{ Tumor size } \\
\hline$\leq 3 \mathrm{~cm}$ & 60 \\
\hline $3-5 \mathrm{~cm}$ & 72 \\
\hline$>5 \mathrm{~cm}$ & 41 \\
\hline \multicolumn{2}{|l|}{ Tumor location } \\
\hline Cervical plexus & 21 \\
\hline Brachial plexus & 32 \\
\hline Thoracic/lumbar root & 35 \\
\hline Lumbar plexus & 1 \\
\hline Upper limb & 31 \\
\hline Lower limb & 50 \\
\hline Other & 3 \\
\hline Mean follow-up (mos) & $112.14 \pm 81.10$ \\
\hline
\end{tabular}


significant at $\mathrm{p}<0.05$. Statistical analyses were conducted using StatView version 5 software (SAS Institute, Inc.).

A literature search was conducted in the PubMed database using, as search terms, "nerve sheath tumor", "schwannoma", "neurofibroma", "MPNST", "PNNST", AND "surgery." A similar search in the Cochrane Library yielded no results. We then excluded review articles, case reports (including series of fewer than 5 cases), articles dealing with purely intradural schwannomas (including vestibular and spinal ones) or orbital schwannomas, and redundant series. The 47 articles included in the review are summarized in Table $2^{2,3,5,7,11,13-15,17,19,21,23,25-27,30,32,35,36,39,42,44,47,48,54,55,57,58}$ and Table 3. $1,6,8-10,12,20,24,29,31,37,38,40,41,46,52,53,56,59$

\section{Results}

\section{Pain, Motor, and Sensory Outcomes}

Comparing preoperative and follow-up scores for all 173 operations, we found a statistically significant improvement in the overall mean values for the VAS score for pain $(3.96 \pm 2.41$ vs $0.95 \pm 1.6, \mathrm{p}=0.0001,95 \% \mathrm{CI}$ $2.69-3.31)$, the motor strength score $(4.38 \pm 0.89$ vs 4.54 $\pm 0.82, \mathrm{p}=0.0146,95 \% \mathrm{CI} 0.043-0.28)$, and the sensory function score $(4.07 \pm 1.22$ vs $4.41 \pm 1.0, \mathrm{p}<0.0001,95 \%$ CI 0.20-0.47) after tumor removal (Fig. 1).

When the cases were stratified by tumor location, type, and size, a statistically significant improvement of motor strength was observed, particularly after surgery for tumors in the brachial plexus ( $\mathrm{p}=0.0457,95 \%$ CI $0.003-$ $0.56)$ and upper limb $(\mathrm{p}=0.0016,95 \%$ CI $0.14-0.49)$, BPNSTs ( $\mathrm{p}=0.0011,95 \%$ CI $0.097-0.36$ ), and tumors with a maximum dimension less than $5 \mathrm{~cm}(\mathrm{p}=0.0187$, $95 \%$ CI $0.029-0.33$ and $\mathrm{p}=0.0021,95 \%$ CI $0.12-0.54$ for $\leq 3 \mathrm{~cm}$ and $3-5 \mathrm{~cm}$, respectively) (Fig. 2).

Regarding sensory function, a statistically significant improvement was observed after surgery for tumors involving the brachial plexus ( $\mathrm{p}=0.0043,95 \%$ CI 0.19-1.05), upper limb ( $\mathrm{p}=0.0016,95 \%$ CI 0.14-0.51), lower limb ( $\mathrm{p}$ $=0.0118,95 \%$ CI $0.083-0.51)$, BPNSTs $(\mathrm{p}<0.0001,95 \%$ CI $0.22-0.54)$, and tumors less than $5 \mathrm{~cm}(\mathrm{p}=0.0003$, 95\% CI $0.16-0.53$ and $\mathrm{p}=0.0001,95 \%$ CI $0.30-0.77$ for $\leq$ $3 \mathrm{~cm}$ and $3-5 \mathrm{~cm}$, respectively) (Fig. 3).

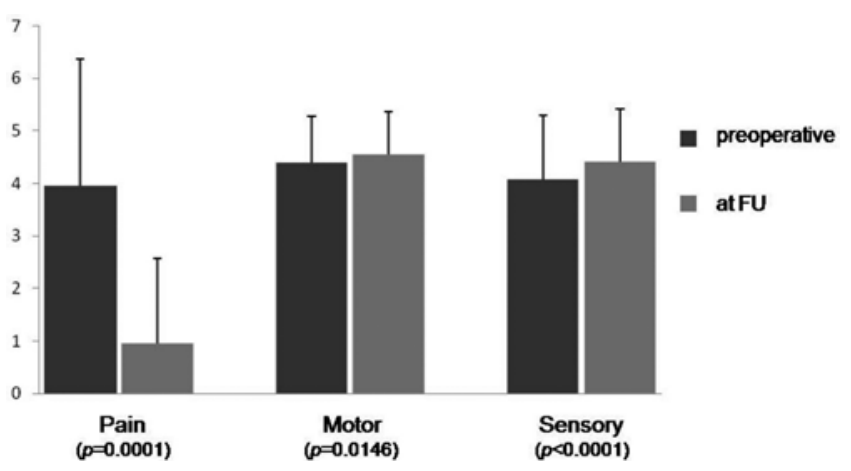

FIG. 1. Bar graph comparing mean scores for pain (VAS), motor strength, and sensory function obtained preoperatively and at follow-up after 173 surgical procedures for resection of peripheral nervous system tumors in 150 patients. (The mean values were calculated based on the number of surgical procedures.) All scores were significantly improved at latest follow-up (FU). Error bars indicate standard error of the mean.

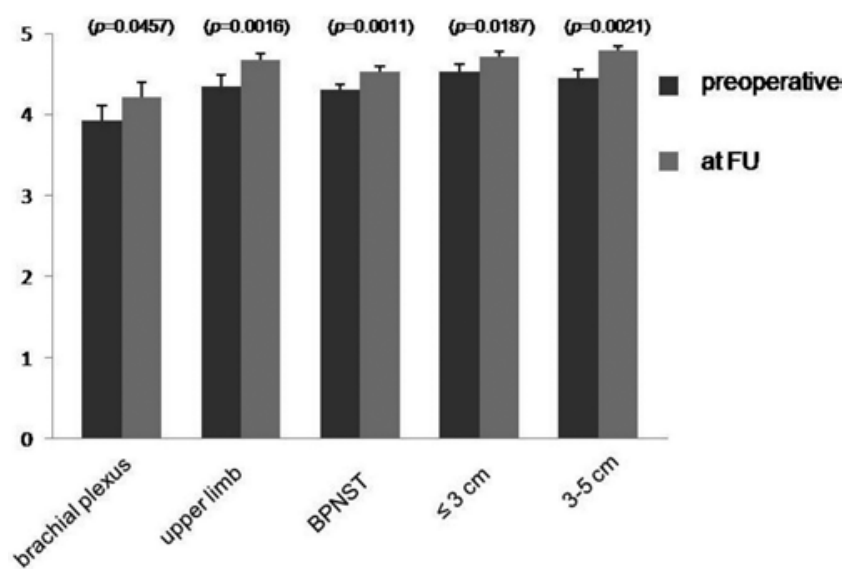

FIG. 2. Bar graph comparing mean motor function scores obtained preoperatively and at follow-up after resection of 173 peripheral nervous system tumors. Motor function scores were significantly improved after resection of brachial plexus and upper-limb tumors, BPNSTs, and tumors less than $5 \mathrm{~cm}$ in maximum dimension. Error bars indicate standard error of the mean.

Considering simultaneously all variables in the statistical comparisons, we found a statistically significant improvement of motor strength after resection of brachial plexus BPNSTs that were $3-5 \mathrm{~cm}$ in maximum dimension $(\mathrm{p}=0.045)$ and upper-limb BPNSTs that were $3 \mathrm{~cm}$ or smaller $(\mathrm{p}=0.014)$ and a statistically significant improvement of sensory function after resection of brachial plexus BPNSTs that were $3-5 \mathrm{~cm}(\mathrm{p}=0.013)$, upper-limb BPNSTs that were $3 \mathrm{~cm}$ or smaller $(\mathrm{p}=0.0082)$, and lowerlimb BPNSTs that were $3-5 \mathrm{~cm}(\mathrm{p}=0.0103)$.

Gross-total resection was achieved in 150 of 173 operations and was associated with statistically significant improvement in motor strength $(\mathrm{p}=0.0251)$ and sensory function $(\mathrm{p}<0.0001)$.

\section{Tumor Recurrence}

We observed recurrence in 14 of 173 tumors. When

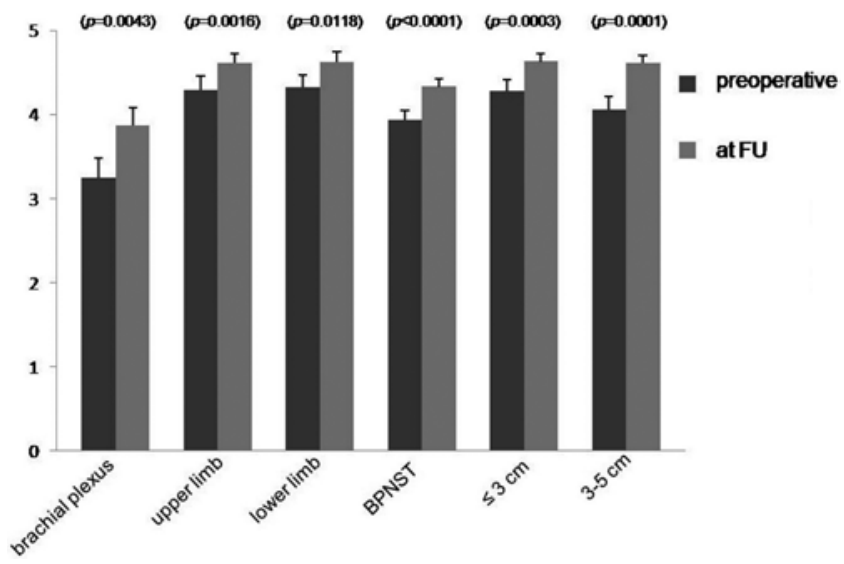

FIG. 3. Bar graph comparing sensory function scores obtained preoperatively and at follow-up after resection of 173 peripheral nervous system tumors. The sensory function score was significantly improved after resection of brachial plexus, upper-limb, and lower-limb tumors as well as after resection of BPNSTs and tumors less than $5 \mathrm{~cm}$ in maximum dimension. Error bars indicate standard error of the mean. 


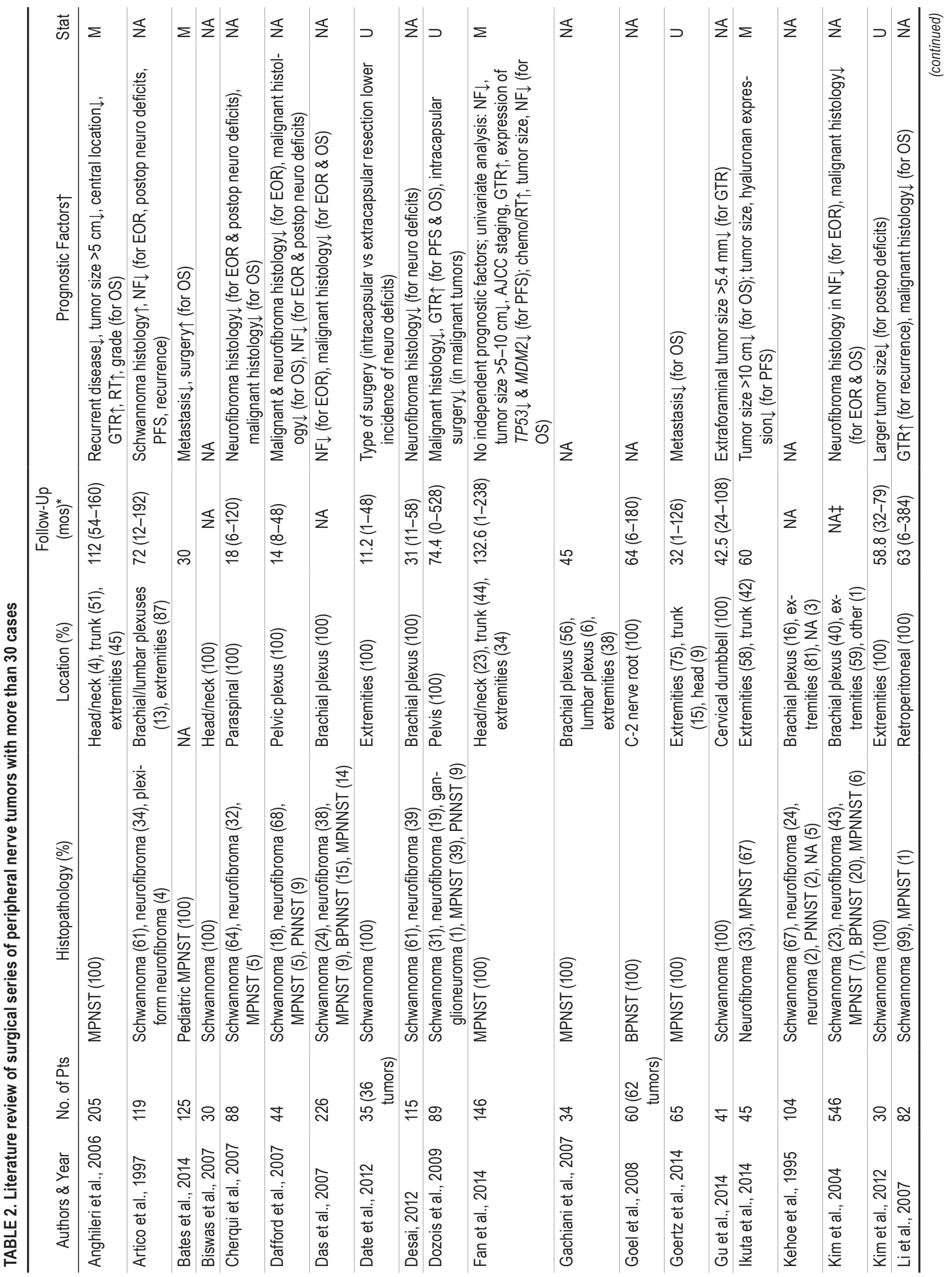




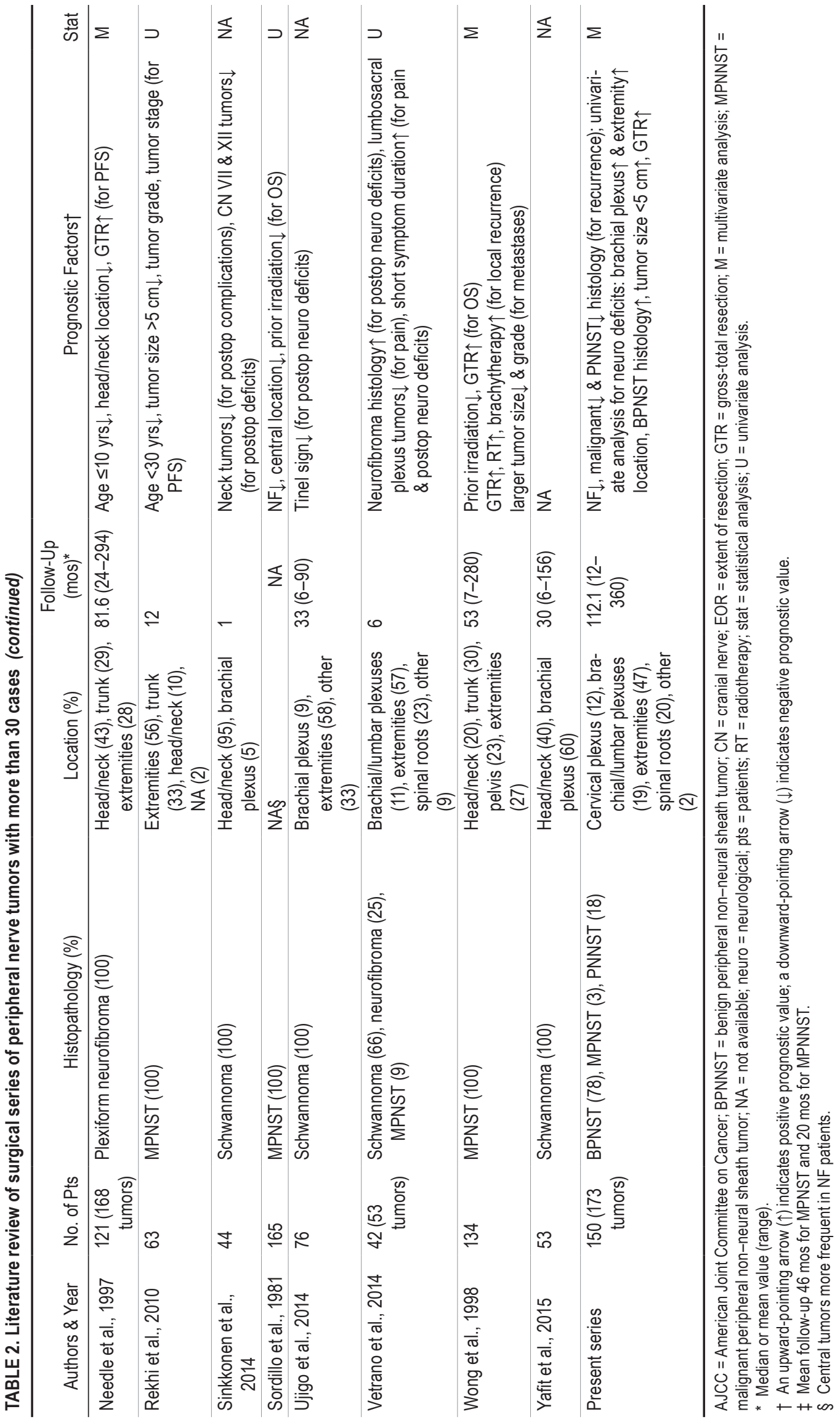




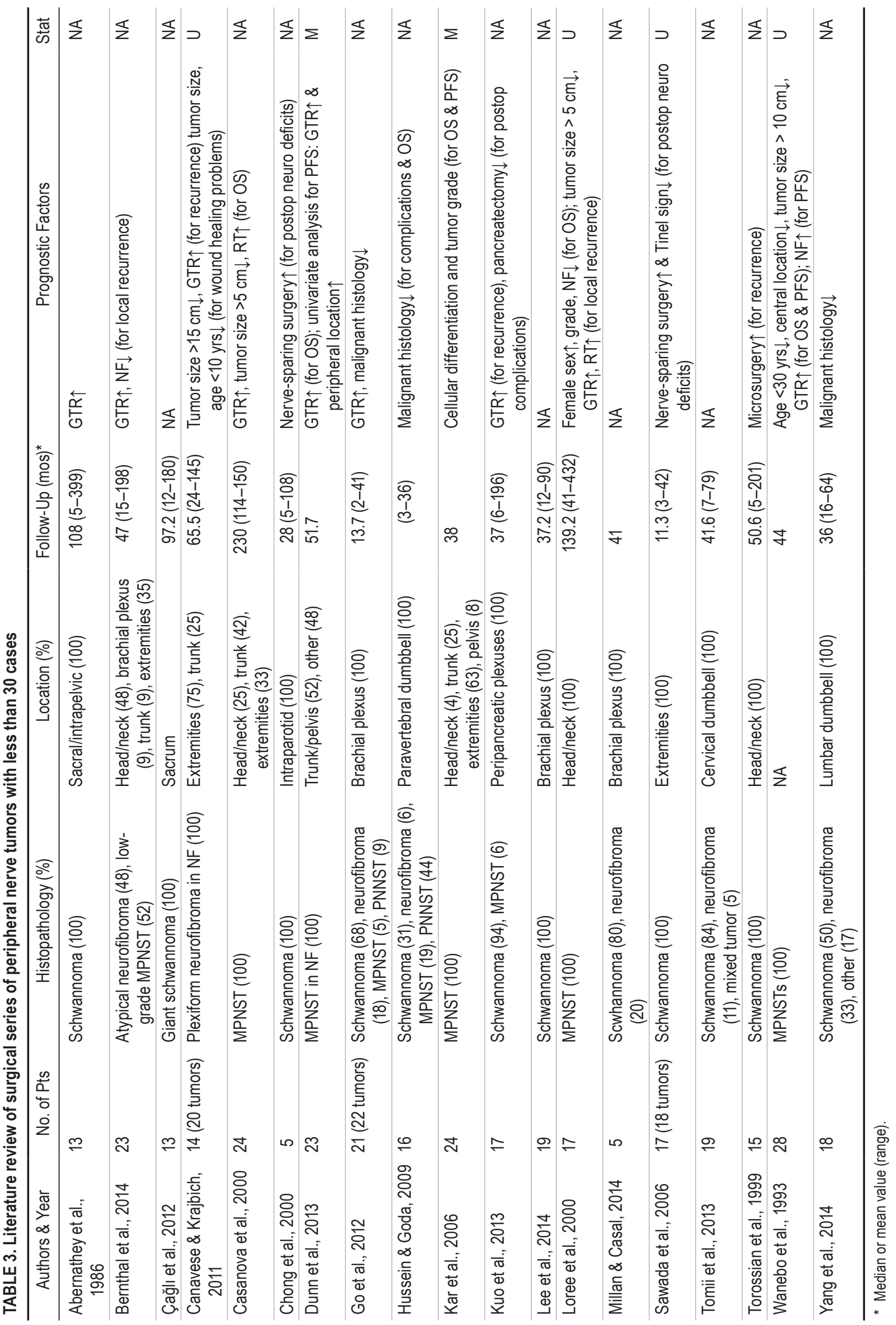


looking at possible prognostic factors we found that a history of NF ( $p=0.0034)$, a diagnosis of MPNST or PNNST $(\mathrm{p}<0.0001)$, and subtotal resection $(\mathrm{p}=0.0042)$ were associated with higher risk of tumor recurrence.

In logistic regression analysis, a history of NF (OR $9.28 \%, 95 \%$ CI 1.62-52.94, $\mathrm{p}=0.0121$ ) and a diagnosis of MPNST (OR $0.03 \%, 95 \%$ CI $0.002-0.429, \mathrm{p}=0.0098$ ) or PNNST (OR 0.081\%, 95\% CI 0.013-0.509, p = 0.0077) emerged as independent prognostic factors for tumor recurrence.

\section{Results From the Literature Review}

Our review of the literature included 28 studies with at least 30 patients or tumors (Table 2) and 19 with less than 30 patients or tumors (Table 3 ). Combining these cases with the present series resulted in a total of 2002 cases of BPNST, 1251 cases of MPNST, and 257 cases of PNNST for analysis, with a mean follow-up of 53.3 months (range 1-112.1 months), 74.8 months (range 6-230 months), and 84.6 months (range 3-119.6 months), respectively. Studies were analyzed for the following parameters, when available: median overall survival (OS) and progression-free survival (PFS), 5- and 10-year OS and PFS, and recurrence rate. With respect to BPNSTs, the median OS and PFS were not reached at the most recent follow-up evaluation in the studies in which these data were available; both 5- and 10-year OS were 100\%, and both 5- and 10-year PFS were $96.4 \%$. The recurrence rate was $3.8 \%$. With respect to MPNSTs, the median OS and PFS were 68.6 months (range 23-132.6 months) and 27.4 months (range 11-57.6 months), respectively; the 5- and 10-year OS were, respectively, $52.7 \%$ and $42.9 \%$; and the 5- and 10-year PFS were, respectively, $36.4 \%$ and $23.3 \%$. The recurrence rate was $43.8 \%$. Insufficient data were available to derive aggregate outcome measures for PNNSTs.

\section{Discussion}

In this study we report the results of our surgical series of BPNSTs, MPNSTs, and PNNSTs. Our approach is to perform a surgical treatment at the first diagnosis in all symptomatic cases and in asymptomatic patients with MRI evidence of increasing tumor size. Moreover, we try to identify possible prognostic factors influencing the clinical outcome (VAS, motor strength score, and sensory score) and the risk of recurrence. In our opinion, the main strengths of this study are the long follow-up, the large number of patients/tumors, and the use of multivariate analysis (regression analysis). In fact, when looking at the literature (see Tables 2 and 3) we found only 3 studies with a duration of follow-up longer than in our series, ${ }^{10,21,40}$ 3 papers with a greater number of patients and wider tumors than our study, 2,14,35 and only a few articles analyzing surgical results and possible prognostic factors using a multivariate analysis. . $^{2,20,21,30,31,42,57}$ The main limit of this study is the retrospective nature of the data, which could affect the results despite the strict statistical analysis.

Considering the impact on clinical outcome, we found an improvement of motor strength and sensory function particularly after resection of tumors located in the brachial plexus and upper limb and BPNSTs. It has been pre- viously demonstrated that some locations can affect the postoperative functional outcome. Sinkkonen et al., in their study of head and neck and brachial plexus schwannomas, ${ }^{47}$ reported that functional outcome was better for patients with brachial plexus tumors and that tumors of the seventh and twelfth cranial nerves were associated with higher rates of postoperative complications and new-onset deficits. Vetrano et al. ${ }^{55}$ showed that tumors located at the lumbosacral plexus were associated with more postoperative pain than tumors in the extremities, brachial plexus, or spinal roots. Moreover, the same authors ${ }^{55}$ showed that a diagnosis of neurofibroma predicts a better functional outcome, although in large series of brachial plexus, ${ }^{3,17}$ lumbar plexus, and extremity, ${ }^{3}$ and paraspinal tumors, ${ }^{11}$ the diagnosis of neurofibroma was associated with a higher risk of developing neurological deficits compared with a diagnosis of schwannoma. However in considering surgical series in which cases of BPNST, MPNST, and PNNST were analyzed together, the histopathological finding of BPNST emerged as a good prognostic indicator for extent of resection, reduced risk of complications, and reduced risk of postoperative deficits. . $^{13,14,29,35}$

We found a statistically significant better functional outcome after resection of tumors that were less than $5 \mathrm{~cm}$ in maximum dimension. The role of tumor size has been the object of extensive investigation in the literature and this factor has been found to be a good prognostic indicator for PFS and OS in various series. 2,5,10,21,30,44,56 Moreover, smaller tumor size has been found to be associated with a lower incidence of postoperative deficit, ${ }^{36}$ local recurrence, ${ }^{9,40}$ and possible metastasis in cases of MPNST. ${ }^{57}$

The extent of resection is another factor frequently analyzed in previous series. In our study we achieved a grosstotal resection in $86.7 \%$ of all the tumors in this series, and gross-total resection was associated with a statistically significant improvement in motor and sensory function. Moreover, we found that a subtotal resection was associated with a higher risk of tumor recurrence. These data are in agreement with previous observations that the extent of resection affects the duration of PFS and $\mathrm{OS}^{2,10,19-21,42,52,56}$ and the risk of recurrence. $6,9,37,39,40,57$

Considering the risk of recurrence in the present series, the variables that emerged as independent prognostic factors were a history of NF and a diagnosis of MPNST or PNNST. When a recurrence is diagnosed at follow-up MRI, our initial approach is "wait and see," performing an MRI study every 3-6 months to detect a lesion increase. In these cases a reoperation is considered with adjuvant radio-chemotherapy if malignant features are observed on histopathological examination.

Although Wanebo et al. ${ }^{56}$ found that NF was associated with better PFS in patients with MPNSTs, data in the literature are otherwise consistent with the finding that a history of NF is associated with a worse prognosis in terms of PFS and OS, 3,21,40,48,56 and recurrence risk. ${ }^{3,6}$ Moreover, data from the literature also support our finding of a strong association between malignant histology and worse prognosis. ${ }^{11,13,14,19,24,29,35,39,59}$ PNNST includes different entities, both benign and malignant, that, in our series, showed a higher risk of recurrence compared with BPNST. This finding could be explained by the fact that, of 32 PNNSTs 
in our series, $13(40.5 \%)$ showed malignant features on histopathology and 5 of these $(38.5 \%)$ recurred after surgery. These findings also seem to be confirmed by series including patients with PNNSTs, especially cases in which malignant features are observed. ${ }^{13,14,19,24,29,35}$

\section{Conclusions}

Tumors of the peripheral nervous system represent a broad spectrum of different pathologies in terms of malignancy and outcome. However, taking into account our results and literature analysis, some conclusions can be drawn. A total resection should always be attempted in all cases of peripheral nerve tumors irrespective of the supposed diagnosis and tumor dimensions, because it is associated with better prognosis in terms of functional outcome and OS in all series. Obviously, it is easier to achieve a total resection in cases of benign tumors with lower dimensions, and this fact explains the better prognosis of these cases (BPNSTs, smaller tumor size). Patients with a history of NF and malignant histology remain a challenge both for neurosurgeons and oncologists due to the higher recurrence rate in these subgroups and the lack of standardized adjuvant therapies.

\section{References}

1. Abernathey CD, Onofrio BM, Scheithauer B, Pairolero PC, Shives TC: Surgical management of giant sacral schwannomas. J Neurosurg 65:286-295, 1986

2. Anghileri M, Miceli R, Fiore M, Mariani L, Ferrari A, Mussi $\mathrm{C}$, et al: Malignant peripheral nerve sheath tumors: prognostic factors and survival in a series of patients treated at a single institution. Cancer 107:1065-1074, 2006

3. Artico M, Cervoni L, Wierzbicki V, D’Andrea V, Nucci F: Benign neural sheath tumours of major nerves: characteristics in 119 surgical cases. Acta Neurochir (Wien) 139:11081116,1997

4. Baehring JM, Betensky RA, Batchelor TT: Malignant peripheral nerve sheath tumor: the clinical spectrum and outcome of treatment. Neurology 61:696-698, 2003

5. Bates JE, Peterson CR, Dhakal S, Giampoli EJ, Constine LS: Malignant peripheral nerve sheath tumors (MPNST): a SEER analysis of incidence across the age spectrum and therapeutic interventions in the pediatric population. Pediatr Blood Cancer 61:1955-1960, 2014

6. Bernthal NM, Putnam A, Jones KB, Viskochil D, Randall RL: The effect of surgical margins on outcomes for low grade MPNSTs and atypical neurofibroma. J Surg Oncol 110:813-816, 2014

7. Biswas D, Marnane CN, Mal R, Baldwin D: Extracranial head and neck schwannomas-a 10-year review. Auris Nasus Larynx 34:353-359, 2007

8. Çağlı S, Işık HS, Yıldırım U, Akıntürk N, Zileli M: Giant sacral schwannomas. J Neurooncol 110:105-110, 2012

9. Canavese F, Krajbich JI: Resection of plexiform neurofibromas in children with neurofibromatosis type 1 . J Pediatr Orthop 31:303-311, 2011

10. Casanova M, Ferrari A, Spreafico F, Luksch R, Terenziani M, Cefalo G, et al: Malignant peripheral nerve sheath tumors in children: a single-institution twenty-year experience. J Pediatr Hematol Oncol 21:509-513, 1999

11. Cherqui A, Kim DH, Kim SH, Park HK, Kline DG: Surgical approaches to paraspinal nerve sheath tumors. Neurosurg Focus 22(6):E9, 2007

12. Chong KW, Chung YF, Khoo ML, Lim DT, Hong GS, Soo
KC: Management of intraparotid facial nerve schwannomas. Aust N Z J Surg 70:732-734, 2000

13. Dafford K, Kim D, Reid N, Kline D: Pelvic plexus tumors. Neurosurg Focus 22(6):E10, 2007

14. Das S, Ganju A, Tiel RL, Kline DG: Tumors of the brachial plexus. Neurosurg Focus 22(6):E26, 2007

15. Date R, Muramatsu K, Ihara K, Taguchi T: Advantages of intra-capsular micro-enucleation of schwannoma arising from extremities. Acta Neurochir (Wien) 154:173-178, 2012

16. Del Grande A, Sabatelli M, Luigetti M, Conte A, Granata G, Rufini V, et al: Primary multifocal lymphoma of peripheral nervous system: case report and review of the literature. Muscle Nerve 50:1016-1022, 2014

17. Desai KI: Primary benign brachial plexus tumors: an experience of 115 operated cases. Neurosurgery 70:220-233, 2012

18. Donner TR, Voorhies RM, Kline DG: Neural sheath tumors of major nerves. J Neurosurg 81:362-373, 1994

19. Dozois EJ, Wall JC, Spinner RJ, Jacofsky DJ, Yaszemski MJ, Sim FH, et al: Neurogenic tumors of the pelvis: clinicopathologic features and surgical outcomes using a multidisciplinary team. Ann Surg Oncol 16:1010-1016, 2009

20. Dunn GP, Spiliopoulos K, Plotkin SR, Hornicek FJ, Harmon DC, Delaney TF, et al: Role of resection of malignant peripheral nerve sheath tumors in patients with neurofibromatosis type 1. J Neurosurg 118:142-148, 2013

21. Fan Q, Yang J, Wang G: Clinical and molecular prognostic predictors of malignant peripheral nerve sheath tumor. Clin Transl Oncol 16:191-199, 2014

22. Ferner RE, O'Doherty MJ: Neurofibroma and schwannoma. Curr Opin Neurol 15:679-684, 2002

23. Gachiani J, Kim D, Nelson A, Kline D: Surgical management of malignant peripheral nerve sheath tumors. Neurosurg Focus 22(6): E13, 2007

24. Go MH, Kim SH, Cho KH: Brachial plexus tumors in a consecutive series of twenty one patients. J Korean Neurosurg Soc 52:138-143, 2012

25. Goel A, Muzumdar D, Nadkarni T, Desai K, Dange N, Chagla A: Retrospective analysis of peripheral nerve sheath tumors of the second cervical nerve root in 60 surgically treated patients. J Neurosurg Spine 8:129-134, 2008

26. Goertz O, Langer S, Uthoff D, Ring A, Stricker I, Tannapfel A, et al: Diagnosis, treatment and survival of 65 patients with malignant peripheral nerve sheath tumors. Anticancer Res 34:777-783, 2014

27. Gu BS, Park JH, Roh SW, Jeon SR, Jang JW, Hyun SJ, et al: Surgical strategies for removal of intra- and extraforaminal dumbbell-shaped schwannomas in the subaxial cervical spine. Eur Spine J [epub ahead of print], 2014

28. Hilton DA, Hanemann CO: Schwannomas and their pathogenesis. Brain Pathol 24:205-220, 2014

29. Hussein HA, Goda HA: Paravertebral neurogenic tumors with intraspinal extension: preoperative evaluation and surgical approach. J Egypt Natl Canc Inst 21:12-22, 2009

30. Ikuta K, Urakawa H, Kozawa E, Arai E, Zhuo L, Futamura $\mathrm{N}$, et al: Hyaluronan expression as a significant prognostic factor in patients with malignant peripheral nerve sheath tumors. Clin Exp Metastasis 31:715-725, 2014

31. Kar M, Deo SV, Shukla NK, Malik A, DattaGupta S, Mohanti BK, et al: Malignant peripheral nerve sheath tumors (MPNST) - clinicopathological study and treatment outcome of twenty-four cases. World J Surg Oncol 4:55, 2006

32. Kehoe NJ, Reid RP, Semple JC: Solitary benign peripheralnerve tumours. Review of 32 years' experience. J Bone Joint Surg Br 77:497-500, 1995

33. Kim DH, Murovic JA, Tiel RL, Moes G, Kline DG: A series of 397 peripheral neural sheath tumors: 30 -year experience at Louisiana State University Health Sciences Center. J Neurosurg 102:246-255, 2005

34. Kim DH, Murovic JA, Tiel RL, Moes G, Kline DG: A series 
of 146 peripheral non-neural sheath nerve tumors: 30 -year experience at Louisiana State University Health Sciences Center. J Neurosurg 102:256-266, 2005

35. Kim DH, Murovic JA, Tiel RL, Kline DG: Operative outcomes of 546 Louisiana State University Health Sciences Center peripheral nerve tumors. Neurosurg Clin N Am 15:177-192, 2004

36. Kim SM, Seo SW, Lee JY, Sung KS: Surgical outcome of schwannomas arising from major peripheral nerves in the lower limb. Int Orthop 36:1721-1725, 2012

37. Kuo TC, Yang CY, Wu JM, Huang PH, Lai HS, Lee PH, et al: Peripancreatic schwannoma. Surgery 153:542-548, 2013

38. Lee HJ, Kim JH, Rhee SH, Gong HS, Baek GH: Is surgery for brachial plexus schwannomas safe and effective? Clin Orthop Relat Res 472:1893-1898, 2014

39. Li Q, Gao C, Juzi JT, Hao X: Analysis of 82 cases of retroperitoneal schwannoma. ANZ J Surg 77:237-240, 2007

40. Loree TR, North JH Jr, Werness BA, Nangia R, Mullins AP, Hicks WL Jr: Malignant peripheral nerve sheath tumors of the head and neck: analysis of prognostic factors. Otolaryngol Head Neck Surg 122:667-672, 2000

41. Millan G, Casal D: Tumors of the brachial plexus in a tertiary referral center: a case series and literature review. Acta Reumatol Port [epub ahead of print], 2014

42. Needle MN, Cnaan A, Dattilo J, Chatten J, Phillips PC, Shochat $\mathrm{S}$, et al: Prognostic signs in the surgical management of plexiform neurofibroma: the Children's Hospital of Philadelphia experience, 1974-1994. J Pediatr 131:678-682, 1997

43. Phalen GS: Neurilemmomas of the forearm and hand. Clin Orthop Relat Res (114):219-222, 1976

44. Rekhi B, Ingle A, Kumar R, DeSouza MA, Dikshit R, Jambhekar NA: Malignant peripheral nerve sheath tumors: clinicopathological profile of 63 cases diagnosed at a tertiary cancer referral center in Mumbai, India. Indian J Pathol Microbiol 53:611-618, 2010

45. Salvati M, Ciappetta P, Raco A, Capone R, Artico M, Santoro A: Radiation-induced schwannomas of the neuraxis. Report of three cases. Tumori 78:143-146, 1992

46. Sawada T, Sano M, Ogihara H, Omura T, Miura K, Nagano A: The relationship between pre-operative symptoms, operative findings and postoperative complications in schwannomas. J Hand Surg Br 31:629-634, 2006

47. Sinkkonen ST, Hildén O, Hagström J, Leivo I, Bäck LJ, Mäkitie AA: Experience of head and neck extracranial schwannomas in a whole population-based single-center patient series. Eur Arch Otorhinolaryngol 271:3027-3034, 2014

48. Sordillo PP, Helson L, Hajdu SI, Magill GB, Kosloff C, Golbey RB, et al: Malignant schwannoma-clinical characteristics, survival, and response to therapy. Cancer 47:25032509, 1981

49. Stark AM, Buhl R, Hugo HH, Mehdorn HM: Malignant peripheral nerve sheath tumours-report of 8 cases and review of the literature. Acta Neurochir (Wien) 143:357-364, 2001

50. Sznajder L, Abrahams C, Parry DM, Gierlowski TC, ShoreFreedman E, Schneider AB: Multiple schwannomas and meningiomas associated with irradiation in childhood. Arch Intern Med 156:1873-1878, 1996
51. Thway K, Fisher C: Malignant peripheral nerve sheath tumor: pathology and genetics. Ann Diagn Pathol 18:109-116, 2014

52. Tomii M, Itoh Y, Numazawa S, Watanabe K: Surgical consideration of cervical dumbbell tumors. Acta Neurochir (Wien) 155:1907-1910, 2013

53. Torossian JM, Beziat JL, Abou Chebel N, DevouassouxShisheboran M, Fischer G: Extracranial cephalic schwannomas: a series of 15 patients. J Craniofac Surg 10:389-394, 1999

54. Ujigo S, Shimose S, Kubo T, Fujimori J, Ochi M: Therapeutic effect and risk factors for complications of excision in 76 patients with schwannoma. J Orthop Sci 19:150-155, 2014

55. Vetrano IG, Lucarella F, Dalolio M, Di Cristofori A, Nataloni IF, Tiberio F, et al: The importance of predicting factors in the surgical outcome of peripheral nerve sheath tumors. J Neurol Surg A Cent Eur Neurosurg 75:104-109, 2014

56. Wanebo JE, Malik JM, VandenBerg SR, Wanebo HJ, Driesen N, Persing JA: Malignant peripheral nerve sheath tumors. A clinicopathologic study of 28 cases. Cancer 71:1247-1253, 1993

57. Wong WW, Hirose T, Scheithauer BW, Schild SE, Gunderson LL: Malignant peripheral nerve sheath tumor: analysis of treatment outcome. Int J Radiat Oncol Biol Phys 42:351360, 1998

58. Yafit D, Horowitz G, Vital I, Locketz G, Fliss DM: An algorithm for treating extracranial head and neck schwannomas. Eur Arch Otorhinolaryngol 272:2035-2038, 2015

59. Yang M, Wang XB, Li J, Xiong GZ, Lu C, Lü GH: Surgical treatment of large abdominally involved primary dumbbell tumor in the lumbar region. J Spinal Disord Tech 27:E268E275, 2014

\section{Disclosures}

The authors report no conflict of interest concerning the materials or methods used in this study or the findings specified in this paper.

\section{Author Contributions}

Conception and design: Montano, Fernandez. Acquisition of data: Montano, D'Alessandris, D'Ercole, Lauretti, Di Bonaventura, La Rocca, Bianchi. Analysis and interpretation of data: Montano, D'Ercole, Fernandez. Drafting the article: Montano, Pallini, Fernandez. Critically revising the article: Montano, D'Alessandris, Fernandez. Reviewed submitted version of manuscript: Montano, D'Alessandris, Fernandez. Approved the final version of the manuscript on behalf of all authors: Montano. Statistical analysis: Montano. Study supervision: Montano, Lauretti, Pallini, Fernandez.

\section{Correspondence}

Nicola Montano, Institute of Neurosurgery, Catholic University, Largo Agostino Gemelli, 8, Rome 00168, Italy. email: nicolamontanomd@yahoo.it. 